\title{
Vídeos sobre Covid-19 para Pessoas com Deficiência: Contribuições da análise à luz da Teoria Cognitiva de Aprendizagem Multimídia
}

\author{
Milena Silva Costa ${ }^{1}$, Evanira Rodrigues Maia ${ }^{1,2}$, Maria Rosilene \\ Cândido Moreira', Andreia Chaves Farias ${ }^{3}$, Joseph Dimas de \\ Oliveira $^{2}$, Antonio Germane Alves Pinto ${ }^{2}$
}

${ }^{1}$ Faculdade de Medicina da Universidade Federal do Cariri, Barbalha, Ceará, Brasil | milena.costa@ufca.edu.br; rosilene.moreira@ufca.edu.br | https://orcid.org/0000-0001-52511927; https://orcid.org/0000-0002-9821-1935

${ }^{2}$ Departamento de Enfermagem da Universidade Regional do Cariri, Crato, Ceará, Brasil | evaniramaia@gmail.com; joseph.oliveira@urca.br; germane.pinto@urca.br | https://orcid.org/0000-0001-9377-7430; https://orcid.org/ 0000-0001-8105-4286; https://orcid.org/0000-0002-4897-1178

${ }^{3}$ Secretaria Municipal de Saúde de Juazeiro do Norte, Ceará, Brasil | andreiacf32@gmail.com | https://orcid.org/0000-0002-1415-6941

Resumo: Introdução: A divulgação de vídeos sobre proteção e prevenção contra a Covid-19 para pessoas com deficiência pode gerar benefícios no sentido de mitigar os casos da doença nesse público. Objetivo: Analisar vídeos divulgados pelas instituições governamentais relacionados à proteção e prevenção da Covid-19 para pessoas com deficiência, à luz da Teoria Cognitiva de Aprendizagem Multimídia. Métodos: Estudo documental, qualitativo, mediante acesso aos sites oficiais das instituições governamentais brasileiras e plataforma de compartilhamentos de vídeos YouTube. Resultados: Foram produzidos 33 vídeos por essas instituições durante o primeiro ano da pandemia, cujos conteúdos apresentaram linguagem compreensível, cores nítidas e variadas, desprovidas de figuras ou animações. $\mathrm{O}$ intérprete de Libras se fez presente em 29 vídeos e em um vídeo houve audiodescrição das imagens. Em 25 vídeos havia legenda em português. Os princípios da Teoria Cognitiva de Aprendizagem Multimídia (TCAM) se fizeram presentes. Os conteúdos eram sobre medidas protetivas da Covid-19, por meio de criação de programas, projetos e serviços que beneficiaram pessoas com deficiência em situação de vulnerabilidade social e econômica, mobilidade no trânsito e projetos para inserção e manutenção delas no mercado de trabalho. Os vídeos abordaram medidas preventivas à Covid-19, como a lavagem das mãos, etiqueta respiratória, uso da máscara, higienização dos equipamentos de apoio, recomendações para os cuidadores/familiares e os serviços disponíveis para suporte. Conclusões: Os princípios da TCAM contribuíram de forma satisfatória nos materiais visuais publicados acerca da Covid19 para as pessoas com deficiência, porém, esta modalidade de comunicação necessita de um maior alcance ao público interessado.

Palavras-chave: Infecções por Coronavírus; Pessoas com Deficiência; Prevenção de Doenças; Webcast.

Videos about Covid-19 for People with Disabilities: Contributions of the analysis in the light of the Cognitive Theory of Multimedia Learning

Abstract. Introduction: The dissemination of videos based on protection and prevention against Covid-19 for people with disabilities can generate benefits in the sense of mitigating cases of the disease in this public. Objective: Analyze videos released by government institutions related to the protection and prevention of Covid-19 in people with disabilities, under Cognitive Theory of Multimedia Learning perspective. Methods: Documentary study, through access to the official websites of Brazilian government institutions and YouTube video sharing platform. Results: It were produced 33 videos by government institutions during the first year of the pandemic. They had understandable language, good quality visuals effects, clear and varied colors, with no virtual figures or animations. The Libras interpreter was present in 29 videos and a video presented audio description of the images. In 25 videos there was subtitles in Portuguese. The principles of Cognitive Theory of Multimedia Learning were present. The contents were about the protective measures of Covid-19, through the creation of programs, projects and services that benefited people with disabilities in situations of social and economic vulnerability, mobility in traffic and projects for their insertion and maintenance in the labor market. . The videos also covered the preventive measures for Covid-19, such as hand washing, respiratory label, wearing a mask, cleaning support equipment, recommendations for caregivers / family members and the services available for support Conclusions: The TCAM principles have contributed satisfactorily to the visual materials published about Covid-19 for people with disabilities, however, this type of communication requires greater reach to the interested public.

Keywords: Coronavirus Infections; Disabled Persons; Prevention of Disease; Webcast. 


\section{Introdução}

A pandemia da Covid-19 causada pelo Coronaviridae (SARS-CoV-2) impacta social, economicamente e na saúde pela velocidade da transmissão, número de acometidos e óbitos. Cepas mais virulentas, destacam o Brasil na disseminação da doença, agravada pelo baixo acesso à vacina e falta de coordenação do governo federal frente à prevenção e controle da doença (Garcia, \& Duarte, 2020).

A pandemia impôs ao poder executivo brasileiro emissão de documentos e produção de conteúdo para orientação preventiva e comunicação para diversos públicos, como pessoas com deficiência $(\mathrm{PcD})$, que apresentam vulnerabilidades específicas.

Informação é medida eficaz para aquisição do conhecimento e exercício dos cuidados preventivos à Covid-19. Tecnologias utilizadas para educação em saúde devem considerar a singularidade das pessoa (Sá et al, 2020). Tecnologias na divulgação científica utilizam imagens paradas (fotografias, desenhos, ilustrações e grafittis) ou em movimento (vídeos, filmes, videoclipes e comerciais publicitários). Os vídeos apresentam maior potencialidade por conjugarem diferentes elementos como imagem em movimento, som, luz e ação (Rose, 2008).

Vídeos disponíveis online são tecnologias de educação e promoção da saúde inclusivas que potencializam o cuidado, por dispor de imagens, animações e/ou sonoplastia, tornando-os atrativos e dinâmicos, despertando interesse pelo aprendizado (Galindo Neto et al, 2019). Tornam-se ferramenta de proteção à saúde, utilizadas pelos governos para garantir regulação dos determinantes de saúde da população (Seta, Oliveira, \& Pepe, 2017). Constituem forma de prevenção que impedem ocorrência das doenças (Rouquayrol, 2017).

Vídeos sobre proteção e prevenção da Covid-19, destinados às $\mathrm{PcD}$, podem gerar conhecimento para mitigar casos pela adotação de medidas por cuidadores/familiares; possibilitar empoderamento e acesso a informação às pessoas sem limitações cognitivas; e, auxiliar tomada de decisão de profissionais da saúde e cuidadores junto a PCD na pandemia.

Objetiva-se analisar vídeos divulgados pelas esferas do executivo na proteção e prevenção da Covid-19 entre $\mathrm{PcD}$, à luz da Teoria Cognitiva de Aprendizagem Multimídia.

\section{Metodologia}

Estudo qualitativo, documental, mediante acesso aos sites oficiais dos governos do poder executivo brasileiro.

Selecionaram-se vídeos publicados de janeiro de 2020 a fevereiro de 2021, com produção de conteúdos governamentais disponíveis nos sites oficiais e plataforma de compartilhamentos de vídeos YouTube, que continham informações sobre medidas protetivas e/ou preventivas da Covid-19 destinados à $\mathrm{PcD}$, contabilizados uma única vez. Realizou-se seleção, classificação, interpretação e codificação dos conteúdos por dois pesquisadores com formação em necessidades especiais e linguagens, que acessaram os sites em dias e locais distintos, para averiguar as compatibilidades.

Utilizou-se check-list com itens: esfera governamental da publicação do vídeo, mês e ano da postagem, disponibilidade na plataforma do YouTube para averiguar repetição, quantidade de visualizações, linguagem adotada, qualidade de recursos visuais, cores das imagens, animações, sonoplastia, tipos de narração e narradores, presença e sexo do Intérprete de Libras, presença e características de legenda em português, audiodescrição das imagens, duração, classificação, título e conteúdo dos vídeos.

O referencial teórico foi a Teoria Cognitiva da Aprendizagem Multimídia (TCAM), a qual explicita que informações multimídias por imagens, palavras narradas ou textuais, animações ou filmes ficam armazenadam na memória de longo prazo do receptor (Almeida et al, 2014). 
Os 12 princípios da Teoria orientam o planejamento e criação de multimídias para apoiar a compreensão de vídeos como forma de aprendizagem: Coerência (exclusão de imagens, palavras e sons dispensáveis); Sinalização (presença de sinais que direcionem a atenção); Redundância (uso de animação e narração ao invés de animação, narração e legenda); Contiguidade espacial (palavras e imagens correspondentes aparecem espacialmente próximas); Contiguidade temporal (palavras e imagens correspondentes aparecem ao mesmo tempo); Segmentação (informação em blocos); Pré-treinamento (apresentação geral do conteúdo antes dos detalhes); Modalidade (animação e narração ao invés de animação e texto escrito); Multimídia (uso de palavras e imagens ao invés de apenas palavras); Personalização (palavras em estilo conversacional, ao invés de estilo formal); Voz (narração com voz humana); Imagem (imagem do narrador não é imprescindível) (Sá et al, 2020).

Após transcrição, realizou-se pré-análise por leituras dos conteúdos, para apreensão temática. $\mathrm{Na}$ exploração do material, codificaram-se dados brutos e transformou-se em informações significativas originando unidades de registro. Na análise temática, os núcleos de sentido foram gerados, considerando aparição e repetição (Bardin, 2016). Os núcleos reunidos por aproximação de significados constituíram categorias de análise, sobre medidas protetivas e preventivas da Covid-19 em PcD. As categorias foram discutidas e argumentadas com base na literatura.

Cumpriu-se preceitos éticos em pesquisa, Resolução 466/12 e 510/16 do Conselho Nacional de Saúde, por vídeos analisados de domínio público.

\section{Resultados}

Encontraram-se 33 vídeos, 13 da esfera federal, 14 estaduais e seis municipais, publicados de março de 2020 a fevereiro de 2021; concentrados nos meses de abril (nove), julho (nove) e março de 2020 (cinco) em estados do Sudeste. 26 disponíveis no site oficial das instituições governamentais e YouTube; 21 vídeos registraram até 500 visualizações e os demais até 44 mil, apenas um vídeo atingiu essa marca.

Os vídeos apresentavam linguagem compreensível, recursos visuais acessíveis, cores nítidas e variadas, com ausência de figuras ou animações. No início de 11 vídeos havia sonoplastia. Em 22 vídeos, apenas uma pessoa discursava o tema. Em um vídeo o conteúdo foi relatado exclusivamente em Libras. Seis vídeos mostravam adultos com deficiência, os demais continham imagens de adultos ou idosos sem deficiência.

Intérprete de Libras presente em 29 vídeos, sendo 20 do sexo masculino. Um vídeo apresentou audiodescrição das imagens para a compreensão das PcD visual. 25 vídeos com legenda em português, tamanhos de letras acessíveis na cor branca, dispostas na parte inferior e plano de fundo preto. Duração de até três horas, concentrados entre $1 \mathrm{a}$ 20 minutos (26 vídeos).

Observou-se planejamento adequado na efetividade cognitiva ao público alvo. Os princípios da TCAM estavam presentes: coerência quando utilizou-se conteúdo visual e sonoro em conformidade as necessidades das PcD; sinalização quando informações sobre as medidas preventivas à Covid-19 foram destacadas em cores e entonação da voz do narrador; redundância e modalidade foram parcialmente atendidos. 32 vídeos tinham narração, nove não apresentavam legendas, um vídeo apresentou conteúdo escrito. Nenhum adotou animação para apresentar o assunto. Os princípios da contiguidade espacial e temporal evidenciaram-se em 23 vídeos.

O princípio da segmentação estava em oito vídeos, contendo os cuidados preventivos por tipo de deficiência apresentados em blocos. Utilizou-se o princípio do pré-treinamento com apresentação geral do conteúdo antes dos detalhes. O princípio multimídia foi atendido no uso de imagens e narração.

O princípio da personalização e da voz atendidos na linguagem compreensível e acessível às $\mathrm{PcD}$. O princípio da imagem foi aplicado em um vídeo, sem expor a imagem do narrador. 
Os 29 vídeos explicativos, os dois vídeos de notícias e duas lives tratavam de conteúdos educativos (17 vídeos) e informativos (16 vídeos) sobre proteção (13 vídeos) e prevenção (20 vídeos) da Covid-19 entre PcD, constituindo duas categorias: Medidas Protetivas e Medidas Preventivas da Covid-19 em PcD.

\subsection{Medidas Protetivas da Covid-19 em PcD}

O Quadro 1 apresenta período de divulgação, títulos e trechos dos conteúdos de 13 vídeos publicados em 2020.

Quadro 1. Medidas Protetivas da Covid-19 em Pessoas com Deficiência. Brasil, 2021.

\begin{tabular}{|c|c|c|}
\hline $\begin{array}{c}\text { Mês/Ano } \\
\text { de Divulgação }\end{array}$ & Título do Vídeo & Trechos do Conteúdo do Vídeo \\
\hline Março/2020 & $\begin{array}{l}\text { Comunicado SEDPcD-SP - Covid- } \\
19\end{array}$ & $\begin{array}{l}\text { A Secretaria de Estado dos Direitos da PcD } \\
\text { informa que os programas, atividades e eventos } \\
\text { agendados em suas dependências estão } \\
\text { suspensos devido a pandemia [...]. }\end{array}$ \\
\hline Março/2020 & $\begin{array}{l}\text { Coletiva de Imprensa - Covid-19 - } \\
\text { 19/03/2020 }\end{array}$ & $\begin{array}{l}\text { Recomenda que as pessoas priorizem e protejam } \\
\text { as pessoas de mais idade e aquelas que têm } \\
\text { doenças crônicas e deficiência, mantendo-as em } \\
\text { casa [...]. }\end{array}$ \\
\hline Abril/2020 & $\begin{array}{l}\text { Comunicado } \quad \text { SPTrans } \quad- \\
\text { Coronavírus }\end{array}$ & $\begin{array}{l}\text { A renovação do Bilhete Único Especial para } P c D \text {, } \\
\text { com prazo de validade nesse período de } \\
\text { quarentena será ampliada automaticamente por } \\
\text { até } 90 \text { dias, sem necessidade de solicitação ou } \\
\text { apresentação de novos laudos. }\end{array}$ \\
\hline Abril/2020 & $\begin{array}{l}\text { Recomendações do Governador } \\
\text { João Doria durante Coletiva de } \\
\text { Imprensa }\end{array}$ & $\begin{array}{l}\text { Recomendação para as pessoas ficarem em casa, } \\
\text { principalmente os idosos, as } P c D \text { e as que tenham } \\
\text { comorbidades que não estejam hospitalizadas. }\end{array}$ \\
\hline Abril/2020 & $\begin{array}{l}\text { Pronunciamento do prefeito Bruno } \\
\text { Covas sobre as ações da } \\
\text { Prefeitura de São Paulo para PcD } \\
\text { em tempos de pandemia. }\end{array}$ & $\begin{array}{l}\text { [...] a Prefeitura de São Paulo criou um Centro } \\
\text { Temporário de Abrigamento (CTA) para população } \\
\text { em situação de rua com algum tipo de } \\
\text { deficiência[...]. O Programa "São Paulo Cidade } \\
\text { Solidária" tem distribuído alimento e recolhido } \\
\text { doações para as famílias que tenham PcD e de } \\
\text { baixa renda que mereçam essa atenção especial. } \\
\text { A Secretaria Municipal da PcD abriu edital para } \\
\text { selecionar até } 20 \text { projetos que possam criar } \\
\text { inclusão e acessibilidade [...]. }\end{array}$ \\
\hline Abril/2020 & $\begin{array}{l}\text { Auxílio emergencial - Passo a } \\
\text { passo }\end{array}$ & $\begin{array}{l}\text { [...] Para acesso ao auxílio emergencial, a PcD tem } \\
\text { que ser maior de idade, não ter emprego formal[...]. }\end{array}$ \\
\hline Abril/2020 & $\begin{array}{l}\text { Acessibilidade é o foco da } \\
\text { Secretaria Nacional dos Direitos da } \\
\text { PcD na pandemia }\end{array}$ & $\begin{array}{l}\text { [...] Garantir a acessibilidade tem sido um dos } \\
\text { maiores desafios do Ministério da Mulher, da } \\
\text { Família e dos Direitos Humanos na crise da } \\
\text { pandemia [...]. }\end{array}$ \\
\hline Junho/2020 & $\begin{array}{l}\text { SEDPcD-SP luta pela inclusão de } \\
\text { todos, mesmo em meio à } \\
\text { pandemia o trabalho continua }\end{array}$ & $\begin{array}{l}\text { [...] Com a pandemia, o curso de Libras está sendo } \\
\text { ofertado com o sistema EAD; o Centro de } \\
\text { Informação à PCD, que atende nas estações do } \\
\text { metrô está digital; o Programa Meu Emprego } \\
\text { Trabalho Inclusivo através do portal, continua para } \\
\text { capacitação e colocação de PCD no mercado de } \\
\text { trabalho. O Programa Todas In-Rede foi criado } \\
\text { com o objetivo de dar empoderamento e } \\
\text { emancipação das mulheres com deficiência, } \\
\text { cuidando e protegendo-as contra violência. Está } \\
\text { acontecendo reabilitacão por teleatendimento. }\end{array}$ \\
\hline Julho/2020 & $\begin{array}{l}\text { Plano garante direitos de PcD e } \\
\text { doenças raras contra Covid-19 }\end{array}$ & $\begin{array}{l}\text { O Governo Federal pretende diminuir o impacto da } \\
\text { pandemia na vida das PCD e doenças raras. A } \\
\text { intenção é dar condições para que elas se } \\
\text { protejam e tenham garantido seus direitos. Está } \\
\text { previsto o lançamento de uma plataforma para } \\
\text { registro de dados sobre doenças raras e sobre } \\
\text { estudantes com deficiência [...]. O Programa Pátria } \\
\text { Voluntária é parceira do Plano de Contingência, já } \\
\text { que vai complementar a ajuda para as PcD } \\
\text { fornecendo alimentos aos que mais precisam e } \\
\text { cursos de capacitação para ingressar no mercado } \\
\text { de trabalho. }\end{array}$ \\
\hline
\end{tabular}




\begin{tabular}{|c|c|c|}
\hline $\begin{array}{c}\text { Mês/Ano } \\
\text { de Divulgação }\end{array}$ & Título do Vídeo & Trechos do Conteúdo do Vídeo \\
\hline Julho/2020 & $\begin{array}{l}\text { Governo Federal lança plano para } \\
\text { diminuir impacto da pandemia na } \\
\text { vida de PcD }\end{array}$ & $\begin{array}{l}\text { [...] a Ouvidoria Nacional dos Direitos Humanos } \\
\text { lançou o aplicativo para celulares, site com } \\
\text { acessibilidade, serviços como chat pelo Telegram } \\
\text { e atendimento em Libras, para aumentar a } \\
\text { acessibilidade ao Disque } 100 \text { e } 180 \text { [...]. }\end{array}$ \\
\hline $\begin{array}{l}\text { Setembro } \\
\quad / 2020\end{array}$ & $\begin{array}{llr}\text { PcD são atendidas com } \\
\text { exclusividade no Centro de } \\
\text { Triagem }\end{array}$ & $\begin{array}{l}\text { [...] Todos os pacientes com deficiência realizaram } \\
\text { o teste para Covid-19, receberam lanches, kit com } \\
\text { álcool gel e máscaras, cestas básicas e kits de } \\
\text { limpeza. }\end{array}$ \\
\hline $\begin{array}{l}\text { Setembro } \\
\quad / 2020\end{array}$ & $\begin{array}{l}\text { Campanha "Eu respeito!" pede } \\
\text { mais empatia em relação às PcD }\end{array}$ & $\begin{array}{l}\text { [...] Eu respeito as vagas para as } P c D \text {, a educação } \\
\text { e o trabalho inclusivo. Respeito as } P c D \text { e com } \\
\text { doenças raras. }\end{array}$ \\
\hline $\begin{array}{l}\text { Dezembro } \\
\text { /2020 }\end{array}$ & $\begin{array}{l}\text { Inclusão de PcD no mercado de } \\
\text { trabalho no contexto da Covid-19 }\end{array}$ & $\begin{array}{l}\text { [...] A Lei } 14.020 \text { trouxe uma garantia provisória de } \\
\text { empregos para trabalhadores com deficiência até } \\
\text { o final da pandemia. Nenhum trabalhador com } \\
\text { deficiência pode ser desligado sem justa causa } \\
\text { [...]. }\end{array}$ \\
\hline
\end{tabular}

\subsection{Medidas Preventivas da Covid-19 em PcD}

No Quadro 2, apresenta-se medidas para reduzir exposição das PcD à Covid-19.

Quadro 2 Medidas para reduzir exposição das PcD à Covid-19.

\begin{tabular}{|c|c|c|}
\hline $\begin{array}{c}\text { Mês/Ano } \\
\text { de Divulgação }\end{array}$ & Título do Vídeo & Trechos do Conteúdo do Vídeo \\
\hline Março/2020 & Nota técnica & $\begin{array}{l}\text { [...] Para o grupo de risco das PcD severa, as medidas devem ser } \\
\text { reforçadas, como higienização frequente das mãos, "etiqueta } \\
\text { respiratória", usar máscara, distanciamento social, evitar aglomerações } \\
\text { [...]. }\end{array}$ \\
\hline Março/2020 & $\begin{array}{l}\text { Covid-19 - Como } \\
\text { Agir }\end{array}$ & $\begin{array}{l}\text { Se a PcD estiver com sintomas de gripe ou resfriado comum, mas com } \\
\text { bom estado de saúde geral, deve permanecer isolado por } 14 \text { dias para } \\
\text { evitar transmissão. Se houver piora dos sintomas, procurar avaliação } \\
\text { médica. }\end{array}$ \\
\hline Março/2020 & $\begin{array}{l}\text { CORONAVÍRUS: } \\
\text { Confira dicas de } \\
\text { higienização para } \\
\text { PcD }\end{array}$ & $\begin{array}{l}\text { [...] as pessoas que utilizam a órtese ou uma prótese, é necessário fazer } \\
\text { a limpeza usando o álcool } 70 \% \text {. [...] Não compartilhe batom [...]. Ao pegar } \\
\text { transporte seria importante que não seja em horário de pico[...]. }\end{array}$ \\
\hline Abril/2020 & $\begin{array}{l}\text { Medidas } \\
\text { importantes para } \\
\text { PCD }\end{array}$ & $\begin{array}{l}\text { A Secretaria de Estado dos Direitos da PcD informa as principais } \\
\text { medidas: indicação dos hospitais para tratamento de casos graves, } \\
\text { funcionamento dos serviços públicos, campanha de vacinação contra a } \\
\text { gripe [...]. }\end{array}$ \\
\hline Abril/2020 & $\begin{array}{lr}\text { Informação } & \text { como } \\
\text { ferramenta } & \text { de } \\
\text { inclusão }- \text { Covid } 19\end{array}$ & $\begin{array}{l}\text { [...] foi produzida uma nota técnica com recomendações ao público com } \\
\text { deficiências, cuidadores e familiares [...]. }\end{array}$ \\
\hline Abril/2020 & $\begin{array}{l}\text { Orientações } \\
\text { prevenção - Covid- } \\
19\end{array}$ & $\begin{array}{l}\text { [...]Deve-se consultar a cartilha elaborada pela Secretaria Nacional de } \\
\text { Direitos da PcD [...] }\end{array}$ \\
\hline Abril/2020 & $\begin{array}{l}\text { Nota técnica em } \\
\text { Libras: cuidados de } \\
\text { proteção } \\
\text { prevenção ao novo } \\
\text { coronavírus para as } \\
\text { PcD }\end{array}$ & $\begin{array}{l}\text { [...] As } P c D \text { que vivem em residências inclusivas, casas geriátricas ou } \\
\text { instituições de longa permanência e os trabalhadores destas, devem } \\
\text { seguir todo o protocolo de medidas preventivas a covid-19 [...]. }\end{array}$ \\
\hline Maio/2020 & $\begin{array}{l}\text { Nota Técnica traz } \\
\text { recomendações às } \\
\text { PcD }\end{array}$ & $\begin{array}{l}\text { [...]A PcD ao ter contato com outras pessoas na rua, lavar o rosto com } \\
\text { água e sabão. Deve-se evitar levar as mãos aos olhos, nariz e boca, pois } \\
\text { são locais de alta contaminação. [...] }\end{array}$ \\
\hline Maio/2020 & $\begin{array}{l}\text { Conheça os } \\
\text { cuidados voltados a } \\
\text { PcD durante a } \\
\text { pandemia }\end{array}$ & $\begin{array}{l}\text { [...]Pessoas que são autistas precisam receber cuidados e ser orientadas } \\
\text { de como lavar as mãos, de como deve comer. Deficiente físico precisa } \\
\text { higienizar as mãos, a cadeira de rodas, a bengala [...]. }\end{array}$ \\
\hline Maio/2020 & $\begin{array}{l}\text { A Organização do } \\
\text { cuidado dos idosos } \\
\text { em ILPI e das PcD } \\
\text { nas Unidades de } \\
\text { Acolhimento } \\
\text { durante a pandemia } \\
\text { provocada pelo } \\
\text { novo coronavírus }\end{array}$ & $\begin{array}{l}\text { [...] As recomendações às instituições e cuidadores são: orientar as } P c D \\
\text { quanto ao risco de contaminação pelo novo coronavírus, por meio de } \\
\text { comunicação fácil e compreensível, resguardando seu grau de cognição } \\
\text { e compreensão [...]. }\end{array}$ \\
\hline
\end{tabular}




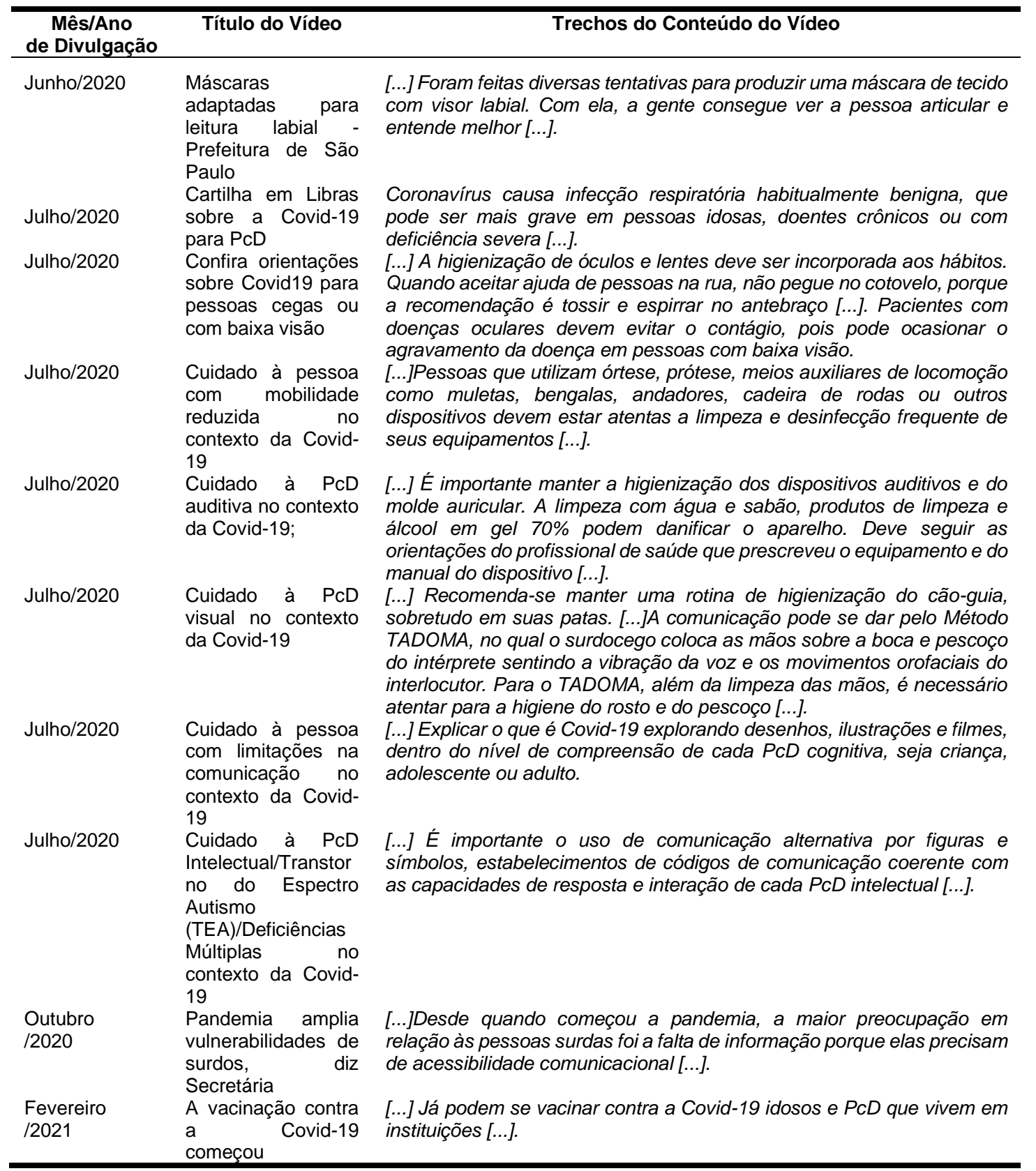

\section{Discussão}

Nos vídeos criados desde o início da pandemia pelas três esferas de governo, adotou-se estratégias educativas em saúde que visam acessibilidade comunicacional e cumprimento dos dispositivos da Lei Brasileira de Inclusão da PcD (Reichenberger et al, 2020).

Porém, pesquisadores têm criticado ausência de coordenação do governo federal no enfrentamento à pandemia voltado as populações mais vulneráveis como PcD (Ferigato, Fernandez, \& Amorim, 2020).

As visualizações dos vídeos foram restritas em relação ao total de $\operatorname{PcD}$ no país. Declararam-se PcD, 45,6 milhões de pessoas no censo brasileiro (IBGE, 2010). Figuram como razões a limitação para compreensão do conteúdo dos vídeos devido ao tipo de deficiência, falta de acessibilidade comunicacional, falta de divulgação sobre a produção deles e barreiras linguísticas (Galindo Neto, 2020). 
É imperativo que produtores de vídeos usem ferramentas adicionais que reduzam as dificuldades vivenciadas pelas PCD e cuidadores/familiares, por meio de linguagem acessível, imagens atrativas e audiodescritivas, cores e som adequados, legendas e presença de intérprete de Libras.

Pesquisa que identificou 37 tradutores-intérpretes de Libras atuando no ensino superior do Brasil, 26 eram do sexo feminino, contrapondo-se ao resultado desse estudo que predominou homens. Tal achado pode relacionar-se a atuação de mulheres na área da educação (Lacerda, \& Gurgel, 2011).

A tradução e a interpretação interlinguística e intermodal, como por exemplo, a Libras, é considerada como uma atividade textual, cognitiva e comunicativa consolidada no país, no sentido de sua importância e legalização. O profissional intérprete de Libras pode atuar nos espaços educacionais, políticos, jurídicos, serviços de saúde e em locais que se façam sua necessidade para comunicação com as pessoas surdas (Gomes, \& Valadão, 2020). A presença destes nos vídeos é essencial para a educação em saúde das $\operatorname{PcD}$ auditiva (Áfio et al, 2016).

A magnitude da Covid-19, direciona olhares de pesquisadores e gestores para buscar medidas de enfrentamento visando reduzir incidência e controlar casos graves (Gurgel et al, 2020). Medidas coletivas prestadas por instituições governamentais foram identificadas no conteúdo dos vídeos.

Adoutou-se estratégias educacionais por meio do ensino remoto e à distância na perspectiva de garantir a continuidade e inclusão aos estudos de PcD (Moreira, Henriques, \& Barros, 2020). Medidas de proteção ao trabalho foram ofertadas por programas inclusivos de incentivo ao emprego e cursos de capacitação para ingressar no mercado de trabalho. Destacou-se a publicação da Lei 14.020, que veda desligamento do emprego sem justa causa de PcD, de forma provisória, até o final da pandemia (Brasil, 2020).

Apesar da produção de conteúdo, evidencia-se fragilidade em alguns estados brasileiros quanto a acessibilidade assistencial e física para as PcD na pandemia, por barreiras comunicacionais, instrumentais e metodológicas no acesso de informações preventivas, serviços de saúde e oferta de educação remota (Böck, Gomes, \& Beche, 2020).

A aplicação dos princípios da Teoria Cognitiva de Aprendizagem Multimídia possibilitou compreender a disposição e o sentido dos conteúdos dos vídeos, além de sua usabilidade e acessibilidade.

Dentre as medidas preventivas às $P C D$ destacou-se higienização das mãos, etiqueta respiratória, distanciamento social, uso de máscara facial e não compartilhamento de cosméticos e utensílios (Garcia, 2020). Ressalta-se que a Lei oㅜ 14.019/2020 garante flexibilização do uso da máscara para alguns grupos de $\mathrm{PcD}$, como aqueles com transtorno do espectro autista, deficiência intelectual, sensoriais ou outras que as impeçam de fazer seu uso adequado (Brasil, 2020).

A orientação para os equipamentos de apoio à $\mathrm{PcD}$, destacam-se tecnologias assistivas, visando à autonomia, inclusão social e qualidade de vida da pessoa que a utiliza (Massaro, \& Deliberato, 2015). Sobre a vacina contra Covid-19, o Ministério da Saúde priorizou, inicialmente, as PcD permanentes e aquelas que vivem em residências inclusivas (Brasil, 2021).

\section{Conclusões}

Os princípios da TCAM foram contemplados satisfatoriamente nos vídeos publicados na prevenção e proteção da Covid-19 entre PcD. Esta modalidade de comunicação necessita de maior alcance ao público interessado. O estudo apresenta como limite a opção apenas dos sites governamentais, sem incluir comentários ou descrição dos vídeos no processo interpretativo. 
O enfoque qualitativo da pesquisa com utilização de informações virtuais evidencia potencial educativo para situações cotidianas no cuidado das PcD. As práticas de autocuidado, proteção e comunicação são tematizadas na produção audiovisual analisada. Destaque-se os desafios de estados e municípios na produção de conteúdo sobre Covid-19 para PcD no cenário brasileiro.

\section{Referências}

Áfio, A.C.E., Carvalho, A.T., Carvalho, L.V., Silva, A.S.R., \& Pagliuca, L.M.F. (2016). Avaliação da acessibilidade de tecnologia assistiva para surdos. Revista Brasileira de Enfermagem, 69(5), 833-839. http://dx.doi.org/10.1590/0034-7167.2016690503.

Almeida, R.R., Chaves, A.C.L., Coutinho, F.A., \& Araújo Júnior, C.F. (2014). Avaliação de objetos de aprendizagem sobre o sistema digestório com base nos princípios da Teoria Cognitiva de Aprendizagem Multimídia. Ciência \& Educação (Bauru), 20(4), 1003-1017. http://dx.doi.org/10.1590/1516-73132014000400015.

Bardin, L. (2016). Análise de conteúdo. São Paulo: Edições 70.

Böck, G.L.K, Gomes, D.M., \& Beche, R.C.E. (2020). A experiência da deficiência em tempos de pandemia: acessibilidade e ética do cuidado. Criar Educação(Criciúma), 9(2), 122-142. http://dx.doi.org/10.18616/ce.v9i2.6049

Brasil. Ministério da Saúde. Secretaria de Vigilância em Saúde. (2021). Plano Nacional de Operacionalização da Vacinação contra a Covid-19. 4ª edição. Brasília, DF.

Brasil. Presidência da República. (2020). Lei no 14.019, de 2 de julho de 2020. Brasília, DF: Diário Oficial da União.

Brasil. Presidência da República. (2020). Lei no 14.020, de 6 de julho de 2020. Institui o Programa Emergencial de Manutenção do Emprego e da Renda e dá outras providências. Brasília, DF: Diário Oficial da União.

Ferigato, S., Fernandez, M., \& Amorim, M. (2020). The Brazilian Government's mistakes in responding to the Covid-19 pandemic. The Lancet, 396(21), 1636. https://doi.org/10.1016/S0140-6736(20)32164-4

Galindo Neto, N.M.S, Guilherme, G.M., Pereira, J.C.N., Barbosa, L.U., Barros, L.M, \& Caetano, J.Á. (2021). Informações sobre Covid-19 para surdos: análise de vídeos do youtube em língua brasileira de sinais. Revista Brasileira de Enfermagem, 74(Suppl. 1), e20200291. https://doi.org/10.1590/0034-7167-2020-0291.

Garcia, L.P, \& Duarte, E. (2020). Intervenções não farmacológicas para o enfrentamento à epidemia da Covid-19 no Brasil. Epidemiologia e Serviços de Saúde, 29(2), e2020222. https://doi.org/10.5123/s1679-49742020000200009

Garcia, L.P. (2020). Uso de máscara facial para limitar a transmissão da Covid-19. Epidemiol. Serv. Saúde, 29(2), e2020023. https://doi.org/10.5123/s1679-49742020000200021

Gomes, E.A., \& Valadão, M.N. (2020). Tradução e interpretação educacional de Libras-língua portuguesa no ensino superior: desdobramentos de uma atuação. Trab. linguist. apl., 59(1), 601-622.https://doi.org/10.1590/010318136376115912020

Gurgel, A.M., Santos, C.C.S., Alves, K.P.S, Araújo, J.M., \& Leal, V.S. (2020). Estratégias governamentais para a garantia do direito humano à alimentação adequada e saudável no enfrentamento à pandemia de Covid-19 no Brasil. Ciência \& Saúde Coletiva, 25(12), 49454956. https://doi.org/10.1590/1413-812320202512.33912020

Instituto Brasileiro de Geografia e Estatística. (2010). Censo 2010: dados preliminares. Brasília: IBGE.

Lacerda, C.B.F., \& Gurgel, T.M.A. (2011). Perfil de tradutores-intérpretes de Libras (TILS) que atuam no ensino superior no Brasil. Rev. bras. educ. espec., 17(3),481-496. https://doi.org/10.1590/S1413-65382011000300009.

Massaro, M., \& Deliberato, D. (2015). Participação da família na confecção de tecnologia assistiva para pessoas com deficiência. Revista de Ciências da Educação, 17(32),163-178. https://doi.org/10.19091/reced.v1i32.394 
Moreira, J.A.M., Henriques, S, \& Barros, D. (2020). Transitando de um ensino remoto emergencial para uma educação digital em rede, em tempos de pandemia. Dialogia, 34(1),351-364. https://doi.org/10.5585/Dialogia.N34.17123

Reichenberger, V., Alburquerque, M.S.V., David, R.B., Ramos, V.D., Lyra, T.M., Brito, C.M.M., Köptcke, L.S., \& Kuper, H. (2020). O desafio da inclusão de pessoas com deficiência na estratégia de enfrentamento à pandemia de Covid-19 no Brasil. Epidemiol. Serv. Saúde, 29(5), e2020770. https://doi.org/10.1590/s1679-49742020000500023.

Rose, D. Análise de imagens em movimento. In: Bauer, M.W, Gaskell, G., organizadores. Pesquisa qualitativa com texto, imagem e som: um manual prático. 2a ed. Petrópolis: Vozes; 2008.

Rouquayrol, M.Z., \& Gurgel, M. (2017). Epidemiologia \& Saúde. 8ª edição. Rio de Janeiro: Medbook.

Sá, G.G.M., Santos, A.M.R., Galindo Neto, N.M., Carvalho, K.M., Feitosa, C.D.A, \& Mendes, P.N. (2020). Construção e validação de vídeo educativo para idosos acerca dos riscos de queda. Revista Brasileira de Enfermagem, 73(Suppl. 3), e20200010. https://doi.org/10.1590/00347167-2020-0010.

Seta, M.H.D., Oliveira, C.V.S., \& Pepe, V.L.E. (2017). Proteção à saúde no Brasil: o Sistema Nacional de Vigilância Sanitária. Ciência \& Saúde Coletiva, 22(10), 3225-3234. http://dx.doi.org/10.1590/1413-812320172210.16672017. 